\title{
Controlled Release Kinetics in Hydroxy Double Salts: Effect of Host Anion Structure
}

\author{
Stephen Majoni ${ }^{1,2}$ and Jeanne M. Hossenlopp ${ }^{1}$ \\ ${ }^{1}$ Department of Chemistry, Marquette University, P.O. Box 1881, Milwaukee, WI 53201-1881, USA \\ ${ }^{2}$ Applied Chemistry Department, National University of Science and Technology, P.O. Box AC 939, Ascot, \\ Bulawayo, Zimbabwe \\ Correspondence should be addressed to Stephen Majoni; majoni_stephen@yahoo.com
}

Received 10 September 2013; Revised 15 December 2013; Accepted 19 December 2013; Published 16 January 2014

Academic Editor: Jan Skov Pedersen

Copyright (C) 2014 S. Majoni and J. M. Hossenlopp. This is an open access article distributed under the Creative Commons Attribution License, which permits unrestricted use, distribution, and reproduction in any medium, provided the original work is properly cited.

\begin{abstract}
Nanodimensional layered metal hydroxides such as layered double hydroxides (LDHs) and hydroxy double salts (HDSs) can undergo anion exchange reactions releasing intercalated anions. Because of this, these metal hydroxides have found applications in controlled release delivery of bioactive species such as drugs and pesticides. In this work, isomers of hydroxycinnamate were used as model compounds to systematically explore the effects of anion structure on the rate and extent of anion release in HDSs. Following intercalation and subsequent release of the isomers, it has been demonstrated that the nature and position of substituent groups on intercalated anions have profound effects on the rate and extent of release. The extent of release was correlated with the magnitude of dipole moments while the rate of reaction showed strong dependence on the extent of hydrogen bonding within the layers. The orthoisomer showed a more sustained and complete release as compared to the other isomers.
\end{abstract}

\section{Introduction}

Nanodimensional layered double hydroxides (LDHs) and hydroxy double salts (HDSs) have been shown to undergo ion exchange reactions with a variety of inorganic and organic ions [1-3]. This ion exchange capability, coupled with the ability to vary the intralayer metal ions, has enabled fine-tuning of these materials for different applications which range from catalysis to isomer separation [3-6]. LDHs and HDSs have a brucite $\left\{\mathrm{Mg}(\mathrm{OH})_{2}\right\}$ type layer structure in which magnesium ions are surrounded by six hydroxide ions in an approximately octahedral geometry with exchangeable anions occupying the interlayer region [7]. LDHs have a general formula $\left[\mathrm{M}^{2+}{ }_{1-x} \mathrm{M}^{3+}{ }_{x}(\mathrm{OH})_{2}\right] \mathrm{A}^{n-}{ }_{x / n} \cdot \mathrm{yH}_{2} \mathrm{O}$ and HDSs can be represented as $\left[\left(\mathrm{M}^{2+}{ }_{1-x} \mathrm{Me}^{2+}{ }_{1+x}\right)(\mathrm{OH})_{3(1-y)}\right] \mathrm{A}^{n-}{ }_{(1+3 y) / n} \cdot \mathrm{mH}_{2} \mathrm{O}$ where $\mathrm{M}^{2+}$ and $\mathrm{Me}^{2+}$ represent different divalent metal ions. In both LDHs and HDSs, $A^{n-}$ is an exchangeable anion which balances the charge and controls the interlayer separation and $d$-spacing.

Anion exchange ability, potential for sustained release, and biocompatibility of the LDHs and HDSs have made them useful in the uptake, storage, and controlled release of bioactive materials such as drugs and plant growth regulators [8-11]. The rate of release of stored drugs and pesticides depends on the intralayer metal composition of the host materials and the size of the intercalated drugs and pesticides $[10,12]$. In addition to the effect of the layer metal ion composition and size of intercalated drugs, the structure of the intercalated drugs is expected to significantly affect their rates of release. In studies involving intercalation reactions, it has been observed that LDHs and HDSs exhibit selectivity when intercalating geometric isomers [5, 13-15]. This selectivity has been attributed to differences in the interaction of the isomers with the metal hydroxide layers due to differences in properties such as dipole moments [13]. Differences in the strength of attraction between the layers and the interlayer anions due to differences in electrostatic interactions have been shown to affect release in LDHs $[16,17]$.

While many studies have been carried out on the applications of LDHs and HDSs in controlled release of pharmaceuticals $[9,10,12]$ and different drugs have been shown to have different release rates $[10,18]$, a systematic 
study on the effect of anion structure on the rate and extent of release is yet to be investigated. In this study, a model system of hydroxycinnamate isomers will be used as model compounds to study the effects of structure on controlled release of anions from HDSs. It is anticipated that this study will help identify structural parameters that can be adjusted in order to enable fine-tuning of rates of release by altering the structure of drugs and pesticides.

\section{Materials and Methods}

2.1. Materials. Copper acetate monohydrate $\left[\mathrm{Cu}\left(\mathrm{C}_{2} \mathrm{H}_{3} \mathrm{O}_{2}\right)_{2}\right.$. $\left.\mathrm{H}_{2} \mathrm{O}\right]$ (98.0\%) was obtained from Alfa Aesar, o-hydroxycinnamic acid $\left[o-(\mathrm{OH}) \mathrm{C}_{6} \mathrm{H}_{4} \mathrm{CHCHCO}_{2} \mathrm{H}\right](98 \%), m$-hydroxycinnamic acid $\left[m-(\mathrm{OH}) \mathrm{C}_{6} \mathrm{H}_{4} \mathrm{CHCHCO}_{2} \mathrm{H}\right](98 \%)$, and $p$-hydroxycinnamic acid $\left[p-(\mathrm{OH}) \mathrm{C}_{6} \mathrm{H}_{4} \mathrm{CHCHCO}_{2} \mathrm{H}\right]$ (98\%) (All isomers were predominantly trans) were obtained from Aldrich Chemical Co. Sodium chloride (100\%) and zinc oxide (100\%) were obtained from J. T. Baker. Sodium hydroxide (pellets, 98\%) was obtained from EMD Chemicals.

2.2. Synthesis of Precursor Zinc Copper Acetate Nanohybrids. Precursor inorganic-organic nanohybrid, zinc copper hydroxy acetate (ZC-Ac), was prepared according to the literature methods [19]. $0.41 \mathrm{~g}$ of $\mathrm{ZnO}$ in $5 \mathrm{~mL}$ of deionized (DI) water was added slowly to a solution of $1.00 \mathrm{~g}$ $\mathrm{Cu}\left(\mathrm{CH}_{3} \mathrm{COO}\right)_{2} \cdot \mathrm{H}_{2} \mathrm{O}$ in $5 \mathrm{~mL}$ of DI water over a period of about 10 minutes. The resultant mixture was stirred frequently at room temperature for 24 hours. The light blue inorganic-organic nanohybrid was filtered, washed several times with DI water, and dried at room temperature.

2.3. Intercalation of Isomers of Hydroxycinnamate ( $n-H C n$ ) into $Z C-A c$. The nanohybrids containing hydroxycinnamate isomers were prepared from $\mathrm{ZC}-\mathrm{Ac}$ by anion exchange; they are referred to herein as $\mathrm{ZC}-\mathrm{o}-\mathrm{HCn}, \mathrm{ZC}-m-\mathrm{HCn}$, and $\mathrm{ZC}-\mathrm{p}-\mathrm{HCn}$ for compounds containing the orthoisomer, metaisomer, and paraisomer, respectively. The conditions for exchange were optimized for each isomer to ensure complete exchange, production of single product phase, and minimization of product degradation. ZC- $\mathrm{Z}-\mathrm{HCn}$ was prepared by mixing $20.0 \mathrm{~g}$ of ZC-Ac with $1000 \mathrm{~cm}^{3}$ of a $0.1 \mathrm{M}$ $o$-hydroxycinnamate $(o-\mathrm{HCn})$ solution at room temperature for 24 hours with frequent stirring; and the exchange reaction was repeated two more times using the same conditions. $\mathrm{ZC}-m$-HCn was prepared by reacting $\mathrm{ZC}$-Ac with $0.5 \mathrm{M} \mathrm{m}$ hydroxycinnamate $(m-\mathrm{HCn})$ solution at $40^{\circ} \mathrm{C}$ for 24 hours with frequent stirring, the exchange was carried out three times under the same condition each time. $1.0 \mathrm{M} p$-HCn was used in the preparation of $\mathrm{ZC}-p$ - $\mathrm{HCn}$ with the exchange reaction being done once at $40^{\circ} \mathrm{C}$, and the higher concentration was necessary to obtain a single $p$ - $\mathrm{HCn}$ phase.

2.4. Characterization. Fourier transform infrared (FTIR) spectra of the nanohybrids were obtained on a Perkin Elmer Spectrum 100 FT-IR spectrometer operated at a $2 \mathrm{~cm}^{-1}$ resolution in the $4000-650 \mathrm{~cm}^{-1}$ spectral range. The obtained spectra were an average of 16 scans. The FTIR spectra were recorded using a single reflection ATR accessory with a ZnSe prism (PIKE MIRacle, from PIKE technology). Elemental analysis was carried out by Huffman labs, Colorado, using atomic emission spectroscopy interfaced with inductively coupled plasma (AES-ICP) for metal determination after qualitative digestion of the nanohybrids. The elements $\mathrm{C}$ and $\mathrm{H}$ were determined by quantitatively digesting the sample through oxidative combustion; nitrogen was analysed using the Kjeldahl method. Position and full width at half maxima (FWHM) for peaks were determined by fitting with Gaussian peak-shape functions.

Powder X-ray diffraction (PXRD) measurements were recorded on a Rigaku Miniflex II diffractometer using $\mathrm{Cu}$ $\mathrm{K} \alpha(\lambda=1.54 \AA)$ radiation source at $30 \mathrm{kV}$ and $15 \mathrm{~mA}$. The diffractometer was calibrated using silicon reference material (RSRP-43275G: manufactured by Rigaku Corporation). The powder samples were pressed into the trough of glass sample holders. The patterns were recorded in the $2 \theta$ range of $2.0^{\circ}-$ $45.0^{\circ}$; data acquisition was performed using a step size of $0.0167^{\circ}$ per second.

2.5. Calculations of Chain Length and Dipole Moments. The chain lengths and dipole moments of carboxylic anions were calculated utilizing the Gaussian 98 program [20] and were carried out at the DFT (B3LYP) level of theory with 6$311++G(d, p)$ basis set. The chain lengths were calculated as the interatomic distance between the center of the carboxyl oxygen and the furthest hydrogen atom.

2.6. Controlled Release Experiments. A batch process was used to study the controlled release of isomers of hydroxycinnamate via anion exchange with chloride ions being used as the exchange anion. The temperature dependence was investigated in the temperature range from $30^{\circ} \mathrm{C}$ to $60^{\circ} \mathrm{C}$. The exchange reactions were performed in a shaking water bath with a temperature stability of $\pm 0.2^{\circ} \mathrm{C}$ and shaking speed of 300 strokes per minute. Several reaction mixtures were prepared by mixing $0.15 \mathrm{~g}$ of the nanohybrids with $15 \mathrm{~mL}$ of a $1.0 \mathrm{M}$ sodium chloride solution and were mechanically shaken in the water bath for a specified time period. The reaction was quenched by filtration followed by washing the residue several times with DI water. Each experiment was repeated at least two times. The solid samples recovered at various contact times were analyzed by PXRD analysis.

The concentrations of released anions $(n-\mathrm{HCn})$ at preset times were monitored by UV-Vis spectroscopy on a Perkin Elmer Lambda 35 UV-Vis spectrophotometer at the characteristic absorbance maximum for each isomer. The selected wavelengths were $270 \mathrm{~nm}$ for $o-\mathrm{HCn}, 272 \mathrm{~nm}$ for $m-\mathrm{HCn}$, and $286 \mathrm{~nm}$ for $p$-HCn. Calibration curves for calculating hydroxycinnamate concentration in aqueous solutions were constructed in the presence of sodium chloride concentrations identical to those used in the exchange reactions. Complete release of the hydroxycinnamate isomers from the nanohybrids was achieved by suspending the nanohybrids in $1.0 \mathrm{M}$ sodium carbonate solution. The concentration of anions released at any given time $t\left(C_{t}\right)$ and the total amount intercalated $\left(C_{\infty}\right)$ were used to calculate 
TABLE 1: Summary of elemental analysis.

\begin{tabular}{lcccc}
\hline \multirow{2}{*}{ Nanohybrid } & \multicolumn{3}{c}{ Elemental analysis (\%): experimental (calculated) } \\
& $\mathrm{Zn}$ & $\mathrm{Cu}$ & $\mathrm{H}$ & $\mathrm{C}$ \\
\hline $\mathrm{ZnCu}_{3.5}(\mathrm{OH})_{6.8}(o-\mathrm{HCn})_{2.2} \cdot 0.8 \mathrm{H}_{2} \mathrm{O}$ & $8.41(8.43)$ & $28.69(28.75)$ & $3.07(3.07)$ & $30.52(30.56)$ \\
$\mathrm{ZnCu}_{2.8}(\mathrm{OH})_{4.8}(m-\mathrm{HCn})_{2.8} \cdot 0.6 \mathrm{H}_{2} \mathrm{O}$ & $8.35(8.27)$ & $22.84(22.61)$ & $3.28(3.24)$ & $38.4(38.01)$ \\
$\mathrm{ZnCu}_{2.5}(\mathrm{OH})_{4.0}(p-\mathrm{HCn})_{3.0} \cdot 0.3 \mathrm{H}_{2} \mathrm{O}$ & $8.27(8.30)$ & $20.03(20.11)$ & $3.32(3.33)$ & $40.58(40.74)$ \\
\hline
\end{tabular}

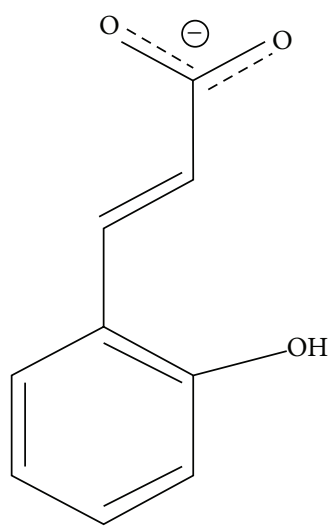

(a)

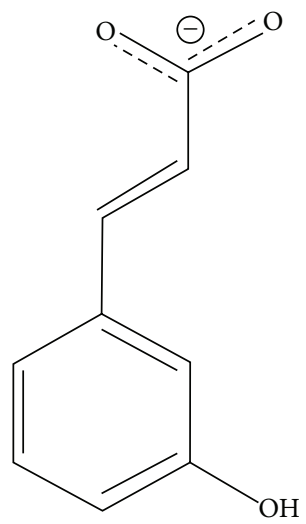

(b)

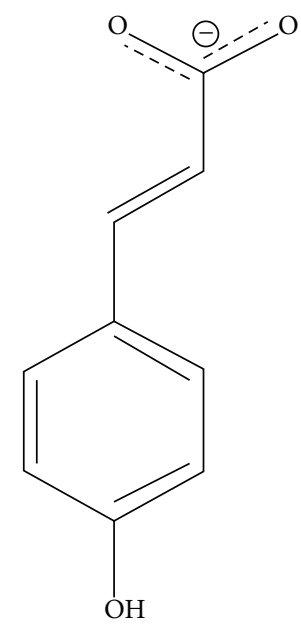

(c)

FIGURE 1: Structure of the anions used in this study: (a) o-hydroxycinnamate $(o-\mathrm{HCn}),(\mathrm{b}) m$-hydroxycinnamate $(m$-HCn) and $(\mathrm{c}) p$ hydroxycinnamate $(p-\mathrm{HCn})$.

the extent of reaction $(\alpha)$ at any given time using (1). $C_{\infty}$ was obtained from complete exchange using carbonate anions and from formulae obtained from elemental analysis (Table S1, see Supplementary Material available online at http://dx.doi.org/10.1155/2014/710487). Equation (1) was also used to obtain extent of ion exchange, (extent of reaction at equilibrium) with $C_{t}$ in (1) now being $C_{t, \infty}$ (amount released at equilibrium).

Consider

$$
\alpha=\frac{C_{t}}{C_{\infty}} .
$$

\section{Results and Discussion}

3.1. Preparation of Hydroxycinnamate Nanohybrids. Hydroxycinnamate exists in 3 geometric isomers as shown in Figure 1. Nanohybrids containing isomers of hydroxycinnamate in the interlayer space were prepared from ZC-Ac by anion exchange. The uptake of these anions and the complete replacement of acetate anions in the interlayer space was confirmed by elemental analysis, PXRD, and ATR-FTIR. The total amount of anions intercalated in the nanohybrids were obtained from both elemental analysis and complete exchange with carbonate anions. The values obtained from both methods are within $10 \%$ as shown in Table S1 in supporting information.

A summary of elemental analysis for the nanohybrids is shown in Table 1. From the formulae obtained from elemental analyses, the ratio of copper to zinc in the metal hydroxide layers of ZC- $m$ - $\mathrm{HCn}$ (2.8) and ZC- $p$ - $\mathrm{HCn}$ (2.5) is comparable to that of the precursor ZC-Ac (2.8) nanohybrid [21]. This may indicate that the exchange reaction in the formation of these compounds was topotactic. The ratio in $\mathrm{ZC}-\mathrm{o}-\mathrm{HCn}$ nanohybrid (3.5) is much higher than in the precursor material which may be an indication that $\mathrm{ZC}-\mathrm{o}-\mathrm{HCn}$ was formed via the dissolution-recrystallization mechanism. In this case, the nature of the cations and anions determines the ratio of the metal ions in the layers which may have resulted in the higher copper content $[7,22]$. XRD profiles indicate that no crystalline copper hydroxide was detected in the material. The low amount of water in the gallery (from Table 1) is consistent with TGA results shown in Figure S1 in supporting information; as an example, TGA results for the degradation of $\mathrm{ZC}-\mathrm{O}$ $\mathrm{HCn}$ indicate that there is $1.6 \%$ weight loss attributed to water loss, and the formula in Table 1 indicates $1.7 \%$ water content.

ZC-Ac used here exhibits a spacing between the planes (d-spacing) of $9.43 \pm 0.03 \AA$ [21] which is comparable to the literature value of $9.46 \AA$ [19]. The PXRD patterns for ZCAc and exchange products are shown in Figure 2(a). All the materials show at least three equally spaced Bragg reflections at low $2 \theta$ values indicating that the materials are layered and possess high range ordering. These basal reflections were used to calculate the $d$-spacing of the materials using the Bragg equation, $n \lambda=2 d \sin \theta$ (where $n$ is the reflection order, $\lambda$ is the wavelength of incident X-ray, $d$ is the spacing between the 

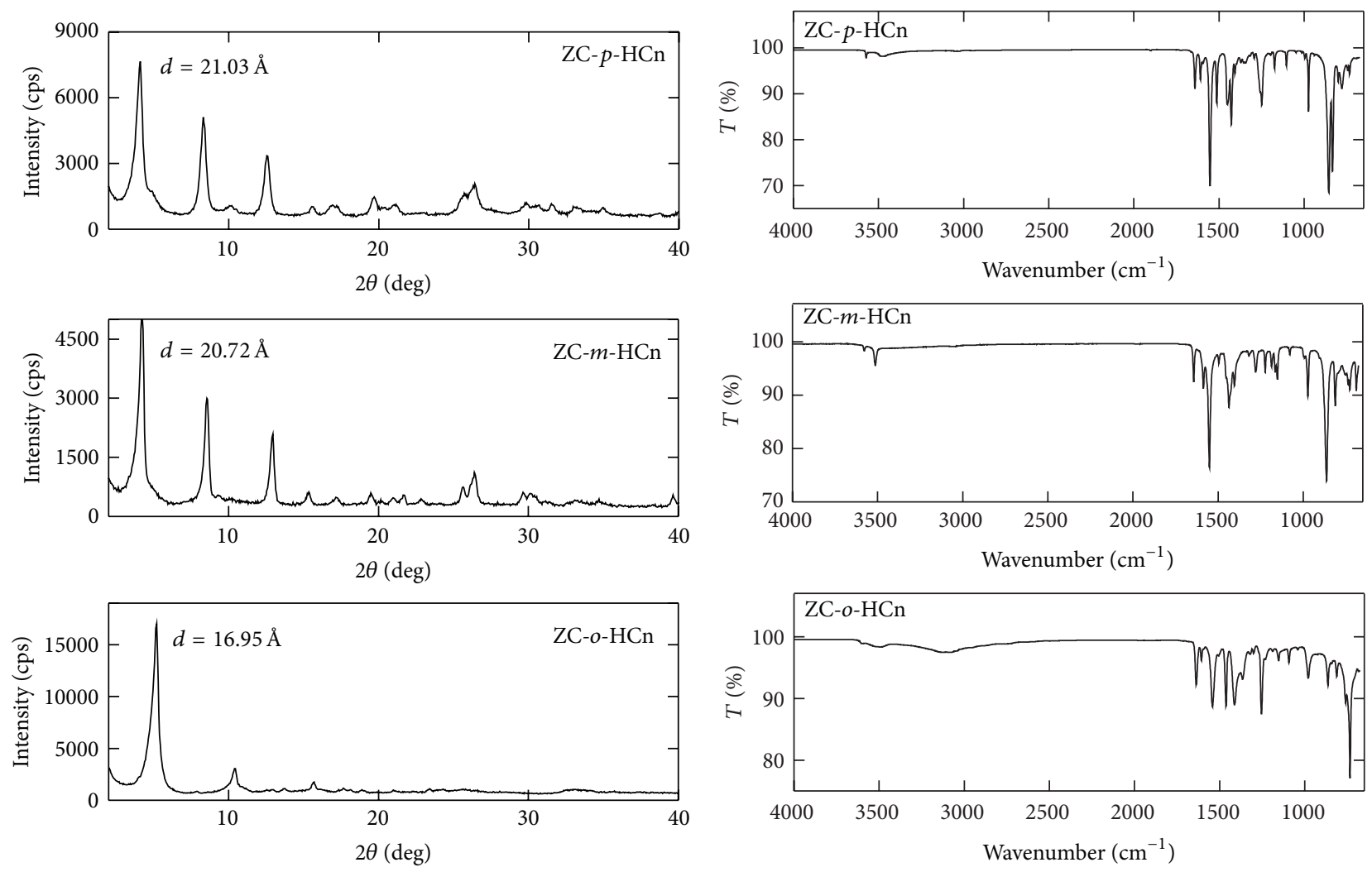

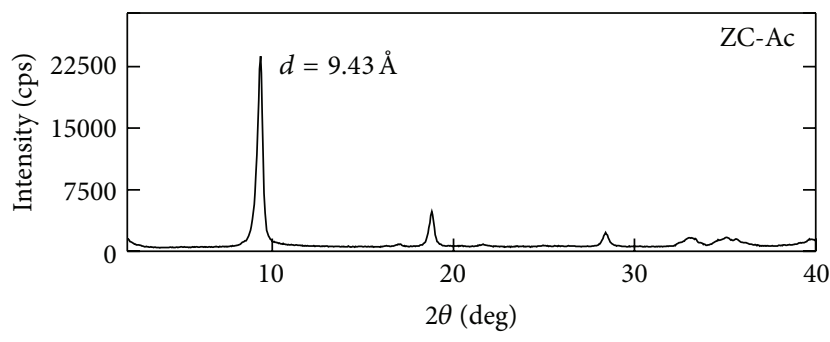

(a)

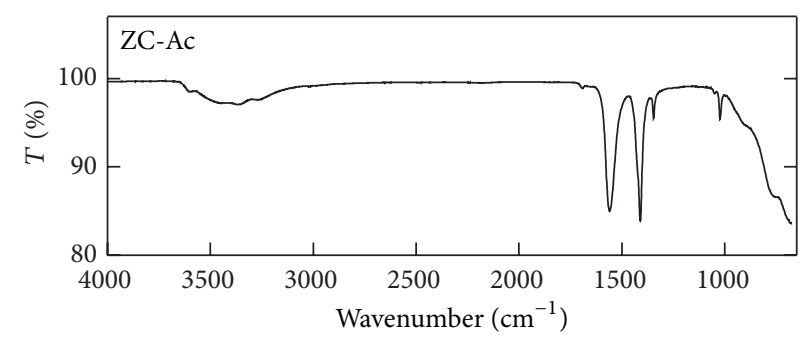

(b)

FIGURE 2: (a) PXRD profiles for ZC-Ac and exchange products and (b) FTIR spectra for ZC-Ac and exchange products.

planes in the lattice, and $\theta$ is the angle between the incident ray and the scattering planes). The Bragg reflections from the precursor material are no longer present in the PXRD traces of the exchange products indicating that the exchange was complete. As revealed in Figure 2(a), there is an increase in the basal spacing as the acetate anion is replaced by $n$ $\mathrm{HCn}$ ions in the interlayer space. The increase in the basal space is consistent with a smaller anion (acetate ion chain length $=1.65 \AA$ ) being replaced by larger $n$ - $\mathrm{HCn}$ anions (chain lengths $=8.63 \AA$ for $o$ - $\mathrm{HCn} ; 8.64 \AA$ for $m$ - $\mathrm{HCn}$, and $9.11 \AA$ for $p-\mathrm{HCn})$. Considering the chain lengths of the metaand paraisomers and the size of the gallery height (about $16 \AA$ if the layer thickness is approximated to be $5 \AA$ as in copper hydroxide) [23], the anions are likely to be arranged in a slightly tilted bilayer orientation. The interlayer space observed in ZC-o-HCn is significantly smaller compared with the other nanohybrids. It was expected that the $d$ spacings would be comparable considering the similarities in the sizes of the isomers. The smaller $d$-spacing in $\mathrm{ZC}-o-\mathrm{HCn}$ might be a result of the orthoisomer being in a more tilted orientation as compared to the other isomers.

IR spectra presented in Figure 2(b) show that when acetate ions were replaced by $n-\mathrm{HCn}$ ions, the peaks due to $\mathrm{C}=\mathrm{O}$ vibrations of acetate ions in $\mathrm{ZC}-\mathrm{Ac}\left(v_{\text {asym }}=1563 \mathrm{~cm}^{-1}\right.$ and $v_{\text {sym }}=1410 \mathrm{~cm}^{-1}$ ) [21] were replaced by a series of peaks $\left(1637-1642 \mathrm{~cm}^{-1}, \mathrm{C}=\mathrm{C} ; 1540-1551 \mathrm{~cm}^{-1}, v_{\text {asym }} \mathrm{C}=\mathrm{O}\right.$; and $\left.1399-1428 \mathrm{~cm}^{-1}, v_{\text {sym }} \mathrm{C}=\mathrm{O}\right)$. The disappearance of vibration peaks from acetate ions is consistent with results inferred from PXRD analysis. The absence of the $\mathrm{C}=\mathrm{O}$ stretching vibration of protonated carboxylic groups which is around $1700 \mathrm{~cm}^{-1}$ confirms that the isomers are present in the ionized form. The full assignment of the IR peaks is found in Table S2 in supplementary information [24].

The hydroxyl stretching vibrational modes (in the region $3000 \mathrm{~cm}^{-1}-3600 \mathrm{~cm}^{-1}$ ) provide information about the interactions in the interlayer space [25]. The structural properties of hydroxyl groups within the interlayer space can be 


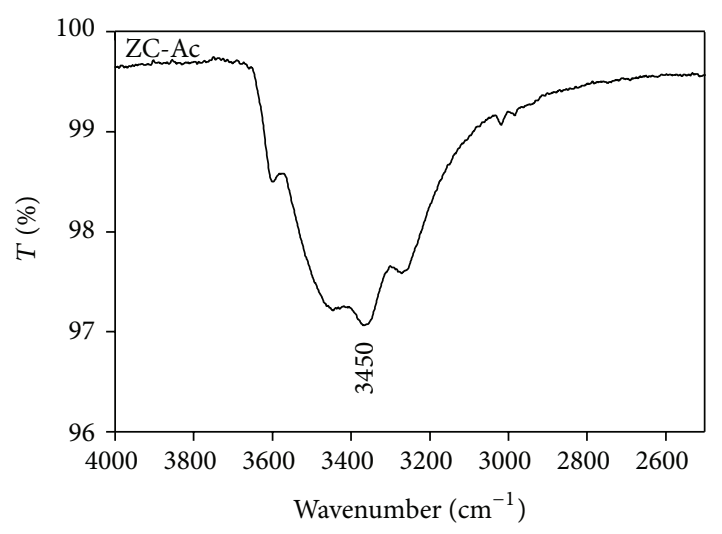

(a)

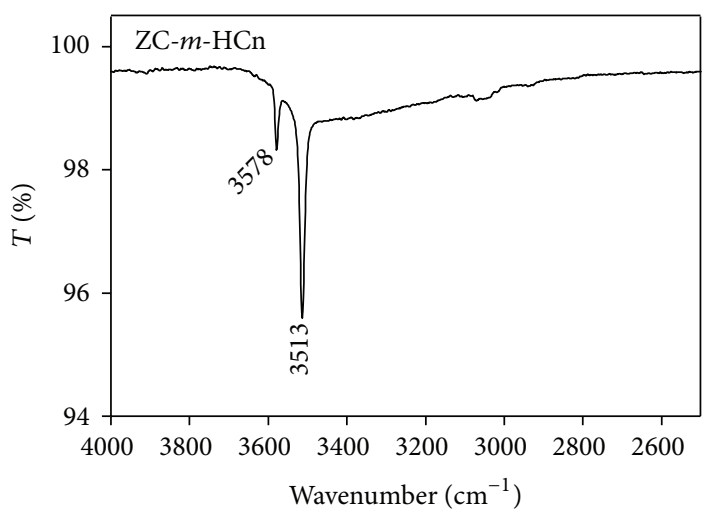

(c)

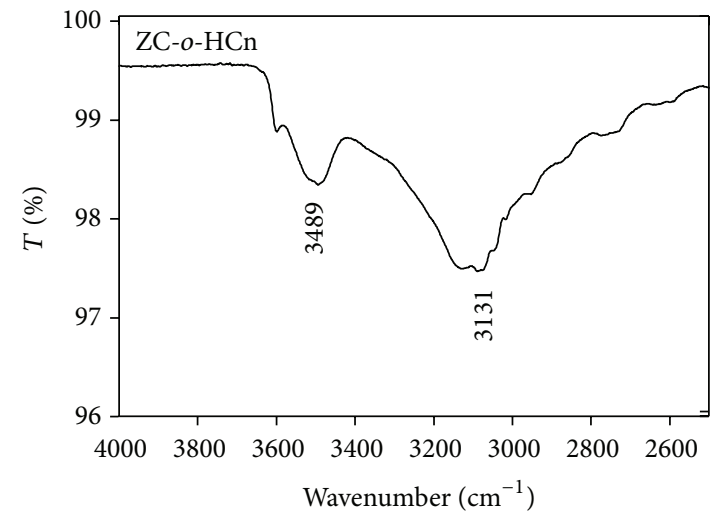

(b)

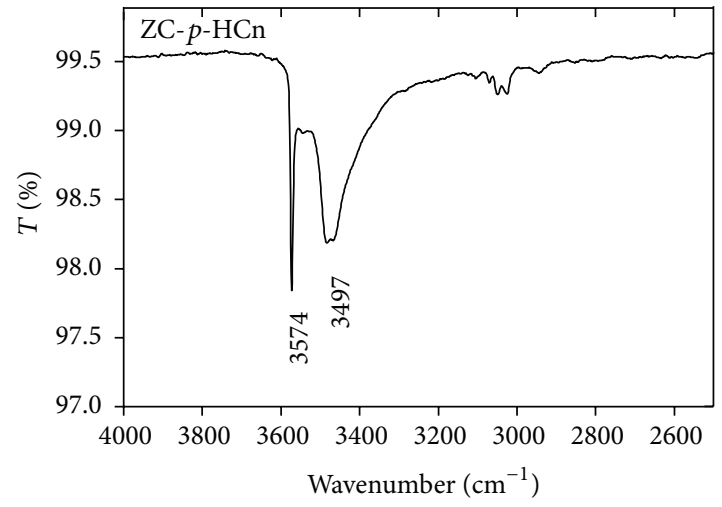

(d)

FIGURE 3: FTIR spectra for ZC-Ac and exchange products showing the hydroxyl stretching region.

correlated to the $\mathrm{OH}$ vibrational modes. Broad absorption bands are associated with stretching modes of hydrogen bonded hydroxyl groups, and sharp bands associated with free hydroxyl groups [26]. The FTIR profiles of the hydroxyl stretching region of ZC-Ac and the exchange products are shown in Figure 3. ZC-Ac has extensive interlayer hydrogen bonding due to intercalated water molecules as reported in our earlier publication [21]. Figure 3 shows that when acetate ions were replaced by $m-\mathrm{HCn}$ ions in $\mathrm{ZC}-m-\mathrm{HCn}$, the broad peak $\left(\mathrm{FWHM}=359 \mathrm{~cm}^{-1}\right)$ centered at $3450 \mathrm{~cm}^{-1}$ in ZC-Ac was replaced by 2 sharp peaks, a strong peak at $3513 \mathrm{~cm}^{-1}\left(\mathrm{FWHM}=14.8 \mathrm{~cm}^{-1}\right)$ and a weak peak at $3574 \mathrm{~cm}^{-1}\left(\mathrm{FWHM}=16.3 \mathrm{~cm}^{-1}\right)$. The two sharp peaks are due to layer $\left(3574 \mathrm{~cm}^{-1}\right)$ and $m$ - $\mathrm{HCn}\left(3513 \mathrm{~cm}^{-1}\right)$ hydroxyl groups which are not involved in substantial hydrogen bonding [25]. This assignment is based on our previous results which showed that the peak at $3513 \mathrm{~cm}^{-1}$ was absent in HDSs containing cinnamate anions (no $\mathrm{OH}$ substitution on the benzene ring) [21]. The shift of the peaks to higher wavenumbers is also indicative of hydroxyl groups which are not substantially involved in hydrogen bonding. ZC-o- $\mathrm{HCn}$ has a very weak peak around $3600 \mathrm{~cm}^{-1}$ and 2 broad peaks centered at $3489 \mathrm{~cm}^{-1}\left(\mathrm{FWHM}=88.0 \mathrm{~cm}^{-1}\right)$ and $3131 \mathrm{~cm}^{-1}$ $\left(\mathrm{FWHM}=376 \mathrm{~cm}^{-1}\right)$. The broadening of peaks and the shift to lower wavenumbers, as compared to vibrations in ZC- $m$ $\mathrm{HCn}$ and free $\mathrm{OH}$ stretching vibrations, is consistent with hydrogen bonded hydroxyl groups [27]. The low intensity of the sharp band at $3600 \mathrm{~cm}^{-1}$ is indicative of extensive hydrogen bonding between layer $\mathrm{OH}$ groups and $o$ - $\mathrm{HCn}$ hydroxyl groups resulting in low density of free layer $\mathrm{OH}$ groups. In ZC-p-HCn, there is a strong sharp peak at $3574 \mathrm{~cm}^{-1}$ (FWHM $=7.2 \mathrm{~cm}^{-1}$ ) which is due to layer $\mathrm{OH}$ groups which are not involved in significant hydrogen bonding and a broad peak at $3497 \mathrm{~cm}^{-1}\left(\mathrm{FWHM}=119 \mathrm{~cm}^{-1}\right)$ due to $p-\mathrm{HCn}$ hydroxyl groups involved in hydrogen bonding.

The absence of strong sharp peaks in $\mathrm{ZC}-o-\mathrm{HCn}$, compared with those observed for ZC-m-HCn and ZC-p-HCn, indicates that there is high level of hydrogen bonding in $\mathrm{ZC}$ $o-\mathrm{HCn}$ relative to the other nanohybrids. Since hydrogen bonding is directional, the $m-\mathrm{HCn}$ anions are not oriented in a way that the $\mathrm{OH}$ groups are able to interact with either the layer $\mathrm{OH}$ groups or groups from other anions. The amount of water in the nanohybrids is low, as indicated from thermogravimetry and elemental analyses. Therefore, having eliminated interlayer water as a likely hydrogen bonding participant, the significant hydrogen bonding observed in ZC-o$\mathrm{HCn}$ and ZC- $p-\mathrm{HCn}$ is most likely intermolecular or between anion and layer hydroxyl groups. In ZC-o- $\mathrm{HCn}$, the $o-\mathrm{HCn}$ hydroxyl group may be in an orientation such that they are close to the layers enabling formation of hydrogen bonds with the layer $\mathrm{OH}$ groups [28]. The interaction between $o-\mathrm{HCn}$ and layer hydroxyl groups may have resulted in the $o-\mathrm{HCn}$ 
TABLE 2: Summary of dipole moments and release data.

\begin{tabular}{|c|c|c|c|c|c|}
\hline \multirow{2}{*}{ Anion } & \multirow{2}{*}{ Equilibrium isomer released at $40^{\circ} \mathrm{C}(\%)$} & \multirow{2}{*}{ Dipole moment } & \multicolumn{3}{|c|}{ Calculated charges } \\
\hline & & & Carbon & Oxygen 1 & Oxygen 2 \\
\hline$o-\mathrm{HCn}$ & 100 & $13.7 \mathrm{D}$ & +0.036 & -0.460 & -0.455 \\
\hline$m$-HCn & 40 & $14.9 \mathrm{D}$ & -0.003 & -0.431 & -0.457 \\
\hline$p-\mathrm{HCn}$ & 22 & $16.7 \mathrm{D}$ & -0.005 & -0.461 & -0.434 \\
\hline
\end{tabular}

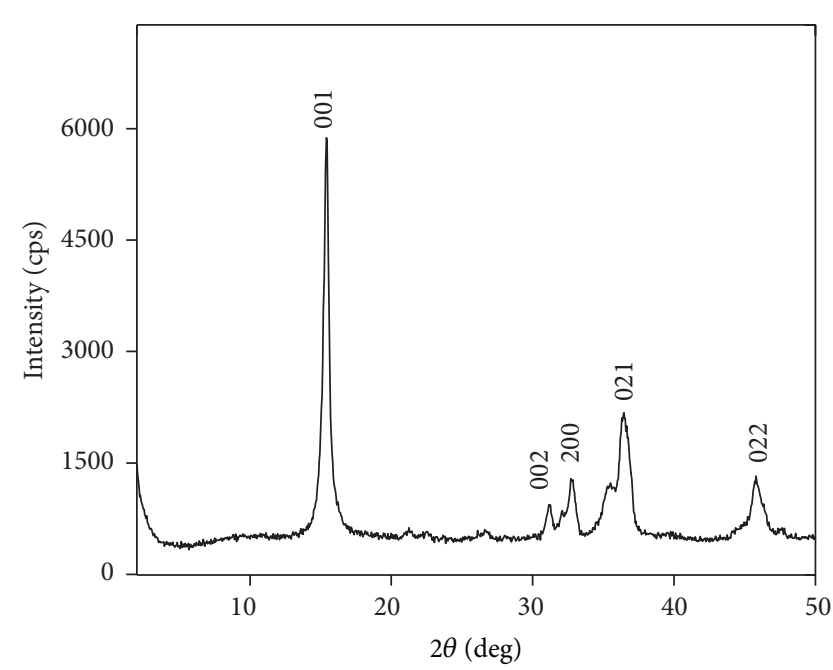

FIgURE 4: PXRD profile of a representative ZC-Cl (kapellasite) obtained from exchange reactions (ZC- $-\mathrm{HCn} / \mathrm{Cl}^{-}$reaction); Miller $h k l$ indices for selected $\mathrm{Cl}^{-}$reflections are given; PDF no. 56-71.

anion being tilted closer to the layers, which may explain the smaller gallery height (as compared to that in $\mathrm{ZC}-m-\mathrm{HCn}$ and $\mathrm{ZC}-p-\mathrm{HCn}$ ) observed from PXRD analysis. In ZC- $p-\mathrm{HCn}$, $\mathrm{OH}$ groups may be oriented in a way so as to participate in intermolecular $\mathrm{H}$-bonding between anions.

3.2. Kinetic Analysis. The release of $n$-HCn from nanohybrids was achieved by ion exchange using $\mathrm{Cl}^{-}$as exchange anions. After specified times, supernatants were collected and analyzed for released anions, and the residues were analyzed for solid state transformations using PXRD. Analysis of the solid samples recovered from the reaction mixtures after each contact time indicated that the same chloride phase was obtained for all the nanohybrids. A representative PXRD profile for the zinc copper chloride $(\mathrm{ZC}-\mathrm{Cl})$ obtained from exchange reactions is shown in Figure 4. The chloride phase has a $d$-spacing of $5.74 \pm 0.01 \AA$ which is in close agreement with the literature value of $5.73 \AA$ [29] and has been indexed as kapellasite $\mathrm{Cu}_{3} \mathrm{Zn}(\mathrm{OH})_{6} \mathrm{Cl}_{2}$ (PDF no. 56-71) [28, 30]. The decrease of the interlayer space as the isomers are released is consistent with large anions being replaced by smaller ions.

The concentrations of released anions were evaluated using UV-Vis spectroscopy. The fractions of released isomers as a function of time (release profiles) at $40^{\circ} \mathrm{C}$ are shown in Figures 5(a)-5(c) for $m-\mathrm{HCn}, o-\mathrm{HCn}$, and $p-\mathrm{HCn}$, respectively. The release profiles at other temperatures show the same general trend and are presented in Figure S2 in the supporting information. Although the chemical structures of the isomers are similar and the release medium is the same, the release profiles and hence release properties are significantly different (Figure 5). The equilibrium amounts released at $40^{\circ} \mathrm{C}$, together with calculated dipole moments and selected atomic charges, are shown in Table 2. As indicated in Table 2, the equilibrium amounts released from the nanohybrids were significantly different. ZC-o-HCn released $100 \%$ of the intercalated ions while $\mathrm{ZC}-m-\mathrm{HCn}$ released about $40 \%$ and ZC- $p$-HCn released about $22 \%$. While ZC-oHCn showed complete release at all temperatures, the extent of reaction for the release of $m-\mathrm{HCn}$ and $p-\mathrm{HCn}$ showed temperature dependence (increasing with temperature as shown in Figure S2). The extents of reactions at $40^{\circ} \mathrm{C}$ are confirmed by XRD data in Figure S3 in supporting information.

The differences in the extent of reaction may indicate differences in the affinity of the HDS for the isomers and differences in the thermodynamic equilibrium constants of the systems. The extent of anion exchange depends on several factors which include the solvation enthalpy of the isomers (in the bulk liquid and in the gallery), the binding enthalpy (between the metal hydroxide layers and the isomers), and the inter-/intramolecular interactions of the anions within the layers $[4,28,31]$. The major contributing factor is expected to be the electrostatic interaction between the positively charged metal hydroxide layers and the negatively charged anions, with the carboxylate group of the isomers being in close contact with the layers. Since the isomers have the same charge and comparable size, differences in dipole moments (an indicator of the charge distribution) could have more influence on the thermodynamics of the release process. The magnitude of dipole moments has been shown to be correlated with selectivity in intercalation reactions of layered double hydroxides $[4,28,31]$. The affinity of the metal hydroxide layer is higher for the isomer with the highest dipole moment [13]; therefore, this isomer is expected to be retained within the layers more than the other isomers.

The equilibrium amounts of anion released from the nanohybrids follow the following order, $o-\mathrm{HCn}>m-\mathrm{HCn}$ $>p$-HCn, which is opposite to that of the magnitude of dipole moments as shown in Table 2. The order of isomer selectivity in intercalation reactions is, as expected, the reverse of the order of equilibrium amount release observed here. Since $p$-HCn has the highest dipole moments, the metal hydroxide layers are expected to have the greatest affinity for $p$-HCn as compared to the other isomers [13]; this could explain the order observed here. Although factors which influence the extent of release are expected to be complex due to the processes involved in anion exchange reactions [32], the results obtained here infer that the magnitude of dipole moments plays a significant role in determining 


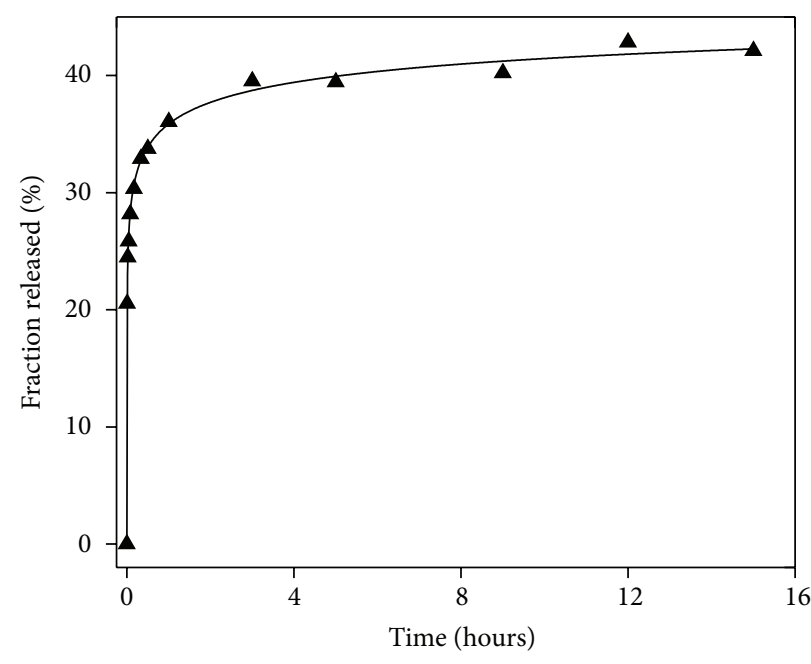

(a)

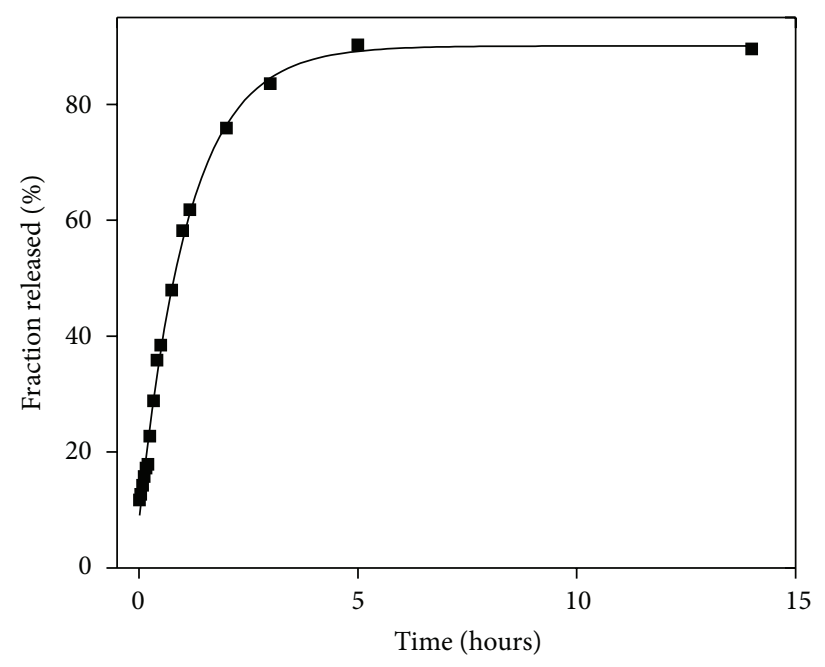

(b)

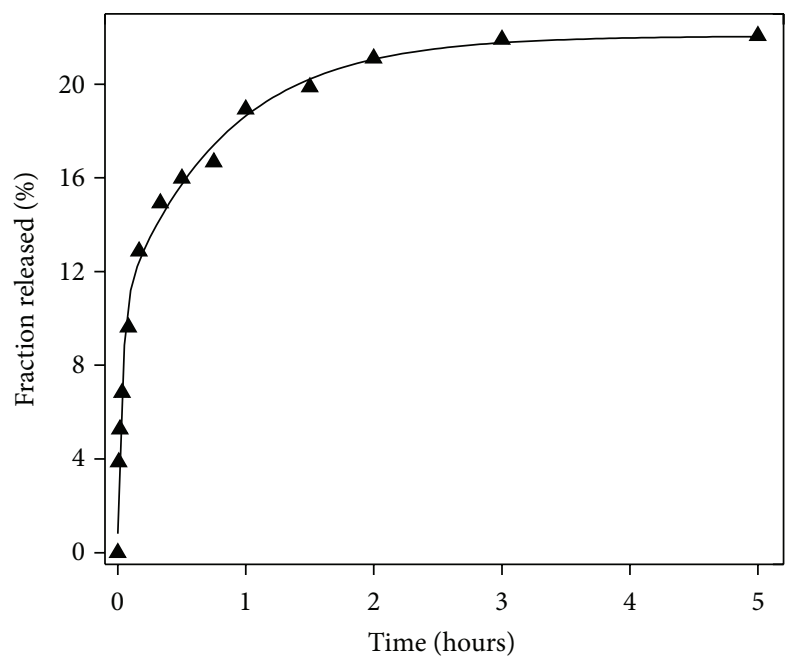

(c)

FIgURE 5: Release profiles for (a) ZC- $m$-HCn, (b) ZC- $o-\mathrm{HCn}$, and (c) ZC-p-HCn at $40^{\circ} \mathrm{C}$.

the equilibrium constant and hence the amount released at equilibrium. The complex nature of the exchange reactions is highlighted when our previous results for the release of cinnamate anion are considered [21]. Cinnamate anion has a dipole moment of $14.6 \mathrm{D}$ which is lower than that of $m$ $\mathrm{HCn}$, but there was only $31 \% \mathrm{Cn}$ released at equilibrium. This indicates a complex interplay of the involved factors as it has been shown that highly hydrophobic anions are easy to intercalate into the layers. Due to the absence of hydroxyl group on the benzene ring of $\mathrm{Cn}$ anion, this isomer is more hydrophobic than the others and is therefore not readily deintercalated into the polar aqueous solvent environment.

From Figure 5, it can qualitatively be observed that the release rates and the release profiles of the isomers are significantly different. While the profiles for $o-\mathrm{HCn}$ release are sigmoidal, those for the meta- and paraisomers are deceleratory. Reaction rates can be quantified by fitting experimental data to reaction models which best describe (reproduce) the experimental data in the so-called model fitting procedure. This procedure is applicable to single mechanism reactions in which the mechanism does not change as the reaction progresses [33]. We have shown previously that isoconversional methods can be extended to anion exchange reactions in layered metal hydroxide as a strategy to identify when using model based approaches are appropriate [21]. A constant $E_{a}$ as a function of extent of reaction indicates that the reaction may effectively be characterized with a single mechanism and in these cases model based procedures are applicable [33]. The integral isoconversional method, (2), was applied to the kinetic data obtained here:

$$
\ln t=\ln \frac{g(\alpha)}{A}+\frac{E_{a}}{R T} .
$$

In (2), $E_{a}$ is the activation energy, $\alpha$ is the extent of reaction, $A$ is the preexponential factor, $t$ is the time, $T$ the temperature, $R$ is the molar gas constant, and $g(\alpha)$ is the integral reaction model. The isoconversional analysis data for all the nanohybrids is shown in Figure 6 in which the $E_{a}$ 


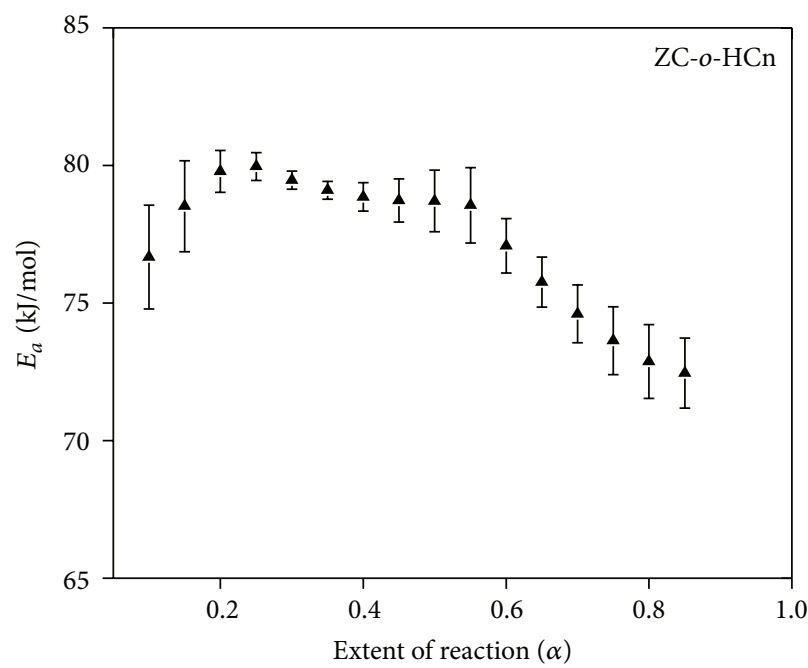

(a)

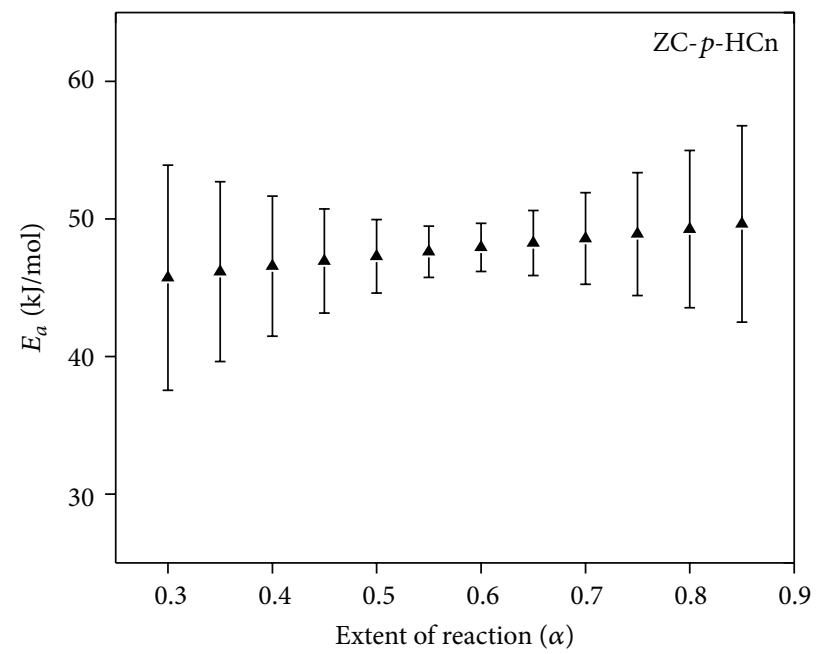

(b)

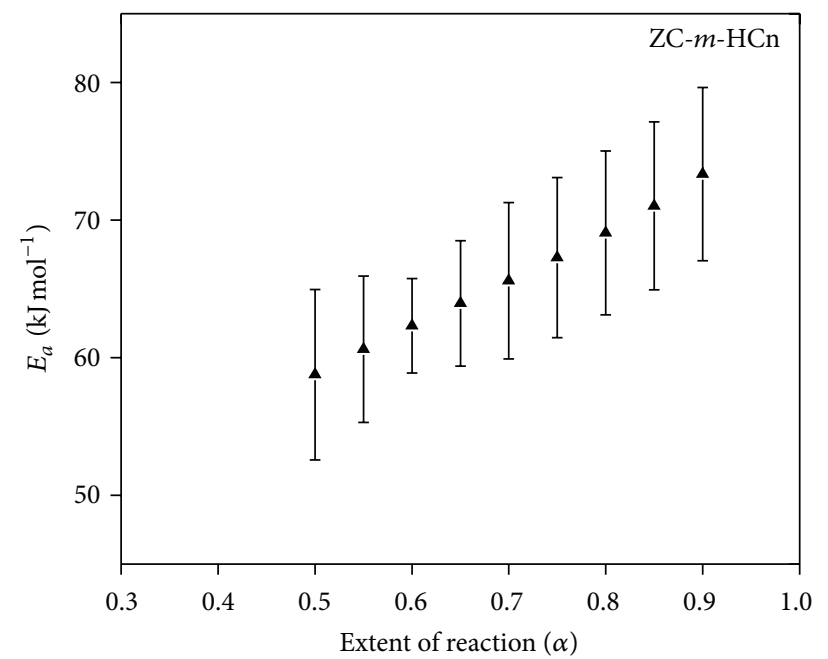

(c)

Figure 6: Variation of effective $E_{a}$ with $\alpha$ for ZC- $m$-HCn, ZC-o-HCn, and ZC- $p$-HCn.

values remains constant, within experimental error, over the entire conversion range for $\mathrm{ZC}-m-\mathrm{HCn}$ and $\mathrm{ZC}-\mathrm{p}-\mathrm{HCn}$.

The $E_{a}$ values for $\mathrm{ZC}-o-\mathrm{HCn}$ are within $10 \%$ although the changes at higher conversion appear significant compared with experimental uncertainty. The linear decrease of the $E_{a}$ at higher conversion, above $\alpha=0.5$, has been attributed to weakening of the electrostatic attraction between the anions and the layers as the anions are progressively exchanged from layer to layer [34]. The constant $E_{a}$ at low conversion may be due to some solid state transformations occurring, which might be responsible for the induction period observed in the PXRD analysis (Figure S3). Although the induction period is short, the process might still be governing the energetics of the reaction even during the exchange period resulting in the constant energy being observed up to extent of reaction of 0.5 . Since $E_{a}$ values for exchange reactions at the anion binding sites have been shown to range from 30 to $70 \mathrm{~kJ} \mathrm{~mol}^{-1}$ depending on the nature and size of the guest anions $[31,32,35]$, the reaction may be controlled by chemical reaction at the exchange site. It is also important to note that diffusion of anions in a dense organic matrix can have high $E_{a}$ values sometimes being more than $100 \mathrm{~kJ} \mathrm{~mol}^{-1}$ [36]; as such diffusion limited process cannot be ruled out if the anions are closely packed in the gallery.

The $E_{a}$ values for the release of $m-\mathrm{HCn}$ and $p$-HCn are in the range of both reaction controlled process and diffusion controlled processes [21]. The fact that the $E_{a}$ does not significantly change over the entire reaction may indicate that the reaction is diffusion controlled. The differences in the mechanism between $o$-HCn release and the other two systems may be due to different strength of interactions with the layers. The presence of $\mathrm{H}$-bonding between the layers and the $o$-HCn anions may bring the anions closer to the layers resulting in an increased electrostatic attraction resulting in the process being controlled by reaction at the exchange site. Since there was no significant variation of the $E_{a}$ with conversion for $m-\mathrm{HCn}$ and $p$ - $\mathrm{HCn}$ release, and the energy difference for $o-\mathrm{HCn}$ release is too low to reflect a change in 
mechanism, model based approach was used to obtain rate constants for the exchange reactions. The Avrami-Erofe'ev nucleation-growth model $[37,38]$ was used here since it has the advantage that it can be used to describe reactions occurring via different mechanisms making comparison of the processes possible since the order of reactions will be the same. In the model, the extent of reaction $(\alpha)$ depends on the rate constant, $k$, and a coefficient, $n$, as shown in the following equation:

$$
a(t)=1-e^{\left[-(k t)^{n}\right]} .
$$

The coefficient $n$ (Avrami exponent) potentially contains information about the mechanism of the reaction [39]. The Avrami-Erofeev model has been applied successfully to solution phase anion exchange reactions in layered materials, and other fluid phase reactions $[2,10,40,41]$; we have also shown that values of parameters obtained from analysis of both solid state transformations and solution phase processes, employing the Avrami model, are comparable indicating that there is correlation between solid state transformation and fluid phase processes [21]. The Avrami exponent is usually obtained by taking double logarithm of the Avrami-Erofeev equation obtaining (4), which was popularized by Sharp and Hancock in 1972 [42]. Consider

$$
\ln [-\ln (1-\alpha)]=n \ln (t)+n \ln (k) .
$$

A plot of $\ln [-\ln (1-\alpha)]$ as a function of $\ln t$ (double logarithmic plot) gives a linear plot in which the value of $n$ is obtained from the slope and the value of $k$ is evaluated from the intercept.

The extent of reaction versus time plots obtained for the $\mathrm{ZC}-o-\mathrm{HCn} / \mathrm{Cl}^{-}$exchange reactions at different temperatures is shown in Figure 7(a). The Avrami-Erofeev model was applied and correctly described the obtained experimental data within the $\alpha$ range of $0.15-1.0$. The validity of the AvramiErofe'ev model can be confirmed by the corresponding double logarithmic plots in Figure 7(b), where straight lines were obtained with $R^{2}$ values ranging from 0.996 to 0.999 . The double logarithmic plots are almost parallel indicating that the reaction proceeds with the same mechanism over the temperature range used here. The obtained $n$ value was close to 1.0 consistent with a nucleation controlled mechanism, which agrees well with the activation energies obtained from isoconversional methods and discussed before.

The release profiles together with the double logarithmic plots for the release of $m-\mathrm{HCn}$ and $p-\mathrm{HCn}$ are shown in the supporting information, Figures S4 and S5, respectively. The kinetics of $m$-HCn release also follows the Avrami-Erofeev model; the data provided a good fit within the range $0.15<$ $\alpha<0.85$; the fit to limited range of $\alpha$ has been observed in other intercalation reactions. Anomalously low values of the Avrami exponent observed here (shown in Table 3) have been reported in polymer and alloy crystallization and do not have physical mechanistic meaning [43, 44]. The Avrami exponent values obtained for the release of $p$-HCn are close to 0.5 which is consistent with diffusion controlled reactions [10]. Diffusion control of such a high $E_{a}$ highlights two

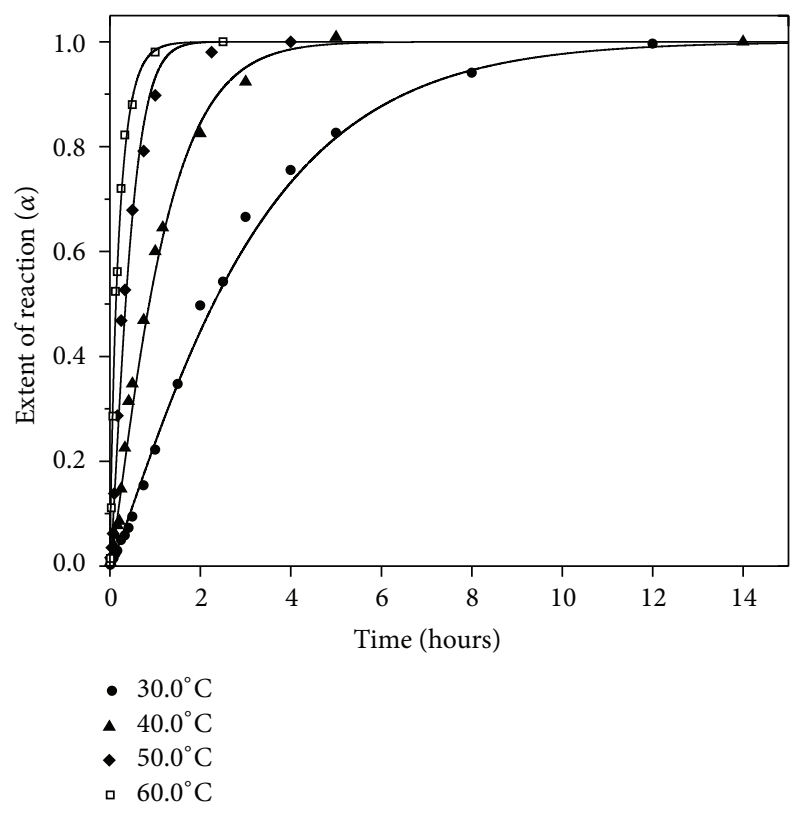

(a)

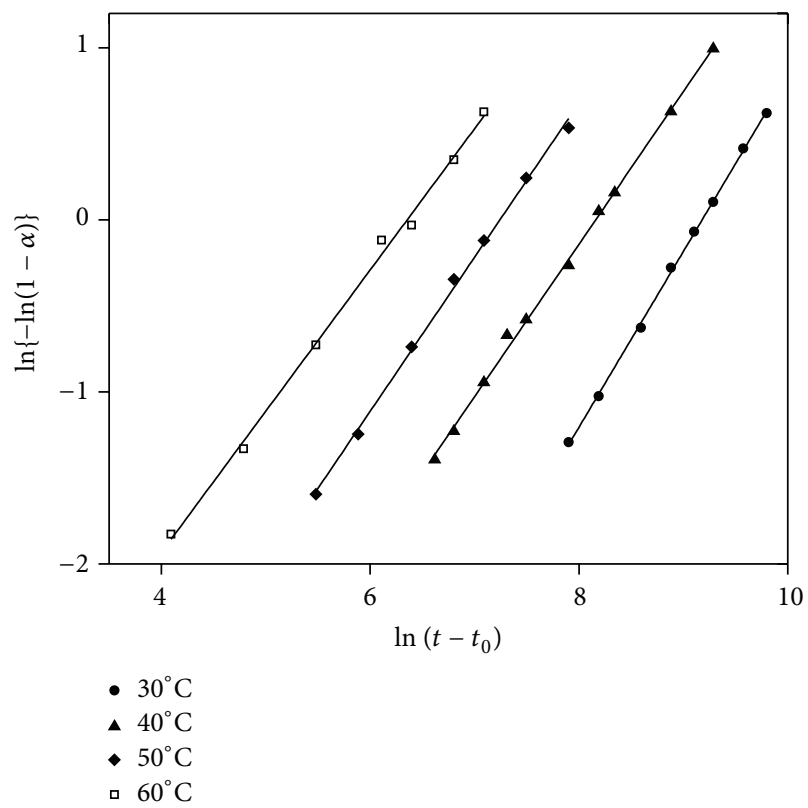

(b)

FIGURE 7: Extent of reaction as a function of time (a) and double logarithmic plots (b), for the exchange reaction of $\mathrm{Cl}^{-}$anion and ZC-o-HCn at various temperatures: $60^{\circ} \mathrm{C}(\square), 50^{\circ} \mathrm{C}(\boldsymbol{\diamond}), 40^{\circ} \mathrm{C}(\boldsymbol{\Delta})$, and $30^{\circ} \mathrm{C}(\bullet)$

issues; (a) the interlayer space is densely packed and the diffusional resistance within the interlayer space approaches that in polymers in which $E_{a}$ values can be above $100 \mathrm{~kJ} \mathrm{~mol}^{-1}$ depending on the diffusing molecule [36] and (b) Kinetic ambiguity is common in model based approaches; in this case, the mechanistic interpretation from the model is not in line with the kinetic parameters obtained.

From Table 3, it can be concluded that the rate of release of $m$-HCn from the nanohybrids is much faster compared with 
TABLE 3: A summary of kinetic parameters obtained at different temperatures.

\begin{tabular}{lccc}
\hline Nanohybrid & Temperature $\left({ }^{\circ} \mathrm{C}\right)$ & $n$ & $k \mathrm{~s}^{-1}\left(* 10^{-3}\right)$ \\
\hline & 60.0 & $0.82 \pm 0.02$ & $1.7 \pm 0.3$ \\
ZC- $o$-HCn & 50.0 & $0.90 \pm 0.02$ & $0.7 \pm 0.1$ \\
& 40.0 & $0.88 \pm 0.01$ & $0.29 \pm 0.05$ \\
& 30.0 & $1.02 \pm 0.01$ & $0.10 \pm 0.01$ \\
\hline ZC- $m$ - $\mathrm{HCn}$ & 60.0 & $0.24 \pm 0.01$ & $31 \pm 9$ \\
& 50.0 & $0.24 \pm 0.01$ & $20 \pm 7$ \\
& 40.0 & $0.21 \pm 0.02$ & 7.2 \\
ZC- $p$ - HCn & 30.0 & $0.225 \pm 0.007$ & $2.9 \pm 0.8$ \\
& 60.0 & $0.41 \pm 0.01$ & $1.6 \pm 0.4$ \\
& 50.0 & $0.45 \pm 0.02$ & $1.0 \pm 0.2$ \\
& 40.0 & $0.46 \pm 0.01$ & $0.5 \pm 0.1$ \\
\hline
\end{tabular}

the other isomers. As an example, the rate constants at $40^{\circ} \mathrm{C}$ were $(7 \pm 2) \times 10^{-3} \mathrm{~s}^{-1}$ for $\mathrm{m}$-HCn, $(1.0 \pm 0.2) \times 10^{-3} \mathrm{~s}^{-1}$ for $p$-HCn, and $(0.29 \pm 0.05) \times 10^{-3} \mathrm{~s}^{-1}$ for $o-\mathrm{HCn}$. The rate of release follows the following order:

$$
m-\mathrm{HCn}>p-\mathrm{HCn}>o-\mathrm{HCn} \text {. }
$$

The release profile for $m-\mathrm{HCn}$ at $40^{\circ} \mathrm{C}$ (Figure 5(a)) shows that there is a burst and rapid release of the intercalated anion in the first 10 minutes followed by a more sustained release with equilibrium being attained after 3 hours. This burst release is observed for all the temperatures used here (Figure S2a in supporting information) and has been observed before in anion exchange reactions in LDHs [10]. The burst release observed here is due to anion exchange as confirmed by PXRD results in Figure S3. The chloride phase, represented by an asterisk in Figure S3, was significant at 30 seconds (the earliest we could sample) of ZC-m-HCn being in contact with the chloride solution. The initial slow and linear release in ZC-o-HCn indicated in Figure 5(b) and confirmed by XRD profiles in Figure S3 may be due to the increased stability of the HDS structure due to extensive hydrogen bonding as indicated by FTIR data in Figure 3 and the close arrangement of the anions implied by XRD profiles in Figure 2(a). This first stage of release has a strong temperature dependence being more pronounced at low temperature and almost absent at higher temperatures (Figure S2b in supporting information).

Factors which may influence the rates of release include interactions between the metal hydroxide layers and the anions, anion-anion interactions within the layers and in the exchange medium, and solvent-anion interaction [10]. It is expected that these factors will have a complex effect on the reaction rates since they affect each isomer differently. The complex interplay of the above mentioned factors often make it difficult to come up with a simple relationship between the rate of release and the aforementioned factors [10]. It is important to note that these factors are expected to depend on the types and positions of chemical groups on the anion. The presence of hydrogen bonding within the interlayer space reduces the Gibbs free energy of formation of the nanohybrids and stabilizes the system [45]. The rate of release of ions then depends on the differences in the energy of nanohybrid and the barrier to reaction. As indicated in Figure 3, there is significant level of hydrogen bonding in ZC-o-HCn which then resulted in a close interaction with the layers. The hydrogen bond network in the nanohybrid and the close interaction of the anions with the layers stabilized the system as compared to the other nanohybrids. The nanohybrid in which these interactions are low is relatively less stable and is expected to proceed faster to equilibrium; this is consistent with results obtained here. The anions in the unstable/less stable nanohybrid prefer bulk solution (in which there is stabilization by solvation with water molecules) to gallery space which may result in the burst and fast release observed in ZC-m-HCn. The modification of bioactive molecules with groups capable of hydrogen bonding, for example, hydroxyl groups, especially at positions which allow interactions with the layers, may enable tuning of the release behavior of these molecules from layered materials. It is important to note that the modification should be at positions which do not affect the bioactivity of the molecules. Additional experiments, including studies on other isomeric anions with groups capable of forming hydrogen bonds and effect of metal layer composition, will be helpful in further elucidating how the position of substituents control the rate as well as the extent of reaction.

\section{Conclusions}

Anion exchange reactions in hydroxy double salts are affected by the structure of the intercalated anions, and there is a strong interplay between thermodynamics and kinetics of the release reactions. In the present study, we have shown that there is a significant effect of the position of substituent groups on the rate and extent of release of isomers of hydroxycinnamate. While the release of the metaisomer was instantaneous and fast, the orthoisomer release exhibited a slower, more sustained, and complete release; the order of reaction rates was $m-\mathrm{HCn}>p-\mathrm{HCn}>o-\mathrm{HCn}$, with the $o$-HCn nanohybrid showing an induction period. The position of the hydroxyl groups resulted in differences in the interlayer interactions of the anions with presence of interlayer hydrogen bonds affecting the rates of the reaction. 
The formation of hydrogen bonds between the layers and the intercalated orthoisomer resulted in greater stabilization of the nanohybrid and resulted in the observed induction period and slow release. The extent of reaction was correlated with the magnitude of dipole moments. These results highlight the potential of tuning the release behavior of intercalated bioactive compounds which bring control into both the amount released per given time and the period for total release.

\section{Conflict of Interests}

The authors declare that there is no conflict of interests regarding the publication of this paper.

\section{Acknowledgment}

This work was supported by the National Science Foundation (CHE-0809751).

\section{References}

[1] S. Yamanaka, T. Sako, and M. Hattori, "Anion exchange in basic copper acetate," Chemistry Letters, pp. 1869-1872, 1989.

[2] E. Kandare and J. M. Hossenlopp, "Hydroxy double salt anion exchange kinetics: effects of precursor structure and anion sizet," Journal of Physical Chemistry B, vol. 109, no. 17, pp. 84698475, 2005.

[3] P. K. Dutta and M. Puri, "Anion exchange in lithium aluminate hydroxides," Journal of Physical Chemistry, vol. 93, no. 1, pp. 376-381, 1989.

[4] B. M. Choudary, V. S. Jaya, B. R. Reddy, M. L. Kantam, M. M. Rao, and S. S. Madhavendra, "Synthesis, characterization, ion exchange, and catalytic properties of nanobinary and ternary metal oxy/hydroxides," Chemistry of Materials, vol. 17, no. 10, pp. 2740-2743, 2005.

[5] A. M. Fogg, J. S. Dunn, S.-G. Shyu, D. R. Cary, and D. O’Hare, "Selective ion-exchange intercalation of isomeric dicarboxylate anions into the layered double hydroxide $\left[\mathrm{LiAl}_{2}(\mathrm{OH})_{6}\right] \mathrm{Cl} \cdot \mathrm{H}_{2} \mathrm{O}$," Chemistry of Materials, vol. 10, no. 1, pp. 351-355, 1998.

[6] T. Ikeda, H. Amoh, and T. Yasunaga, "Stereoselective exchange kinetics of $\mathrm{L}$ - and $\mathrm{D}$-histidines for $\mathrm{Cl}$ - in the interlayer of a hydrotalcite-like compound by the chemical relaxation method," Journal of the American Chemical Society, vol. 106, no. 20, pp. 5772-5775, 1984.

[7] M. Meyn, K. Beneke, and G. Lagaly, "Anion-exchange reactions of hydroxy double salts," Inorganic Chemistry, vol. 32, no. 7, pp. 1209-1215, 1993.

[8] V. Ambrogi, G. Fardella, G. Grandolini, L. Perioli, and M. C. Tiralti, "Intercalation compounds of hydrotalcite-like anionic clays with anti-inflammatory agents, II: uptake of diclofenac for a controlled release formulation," AAPS PharmSciTech, vol. 3, no. 3, p. E26, 2002.

[9] M. Z. Bin Hussein, Z. Zainal, A. H. Yahaya, and D. W. V. Foo, "Controlled release of a plant growth regulator, $\alpha$ naphthaleneacetate from the lamella of Zn-Al-layered double hydroxide nanocomposite," Journal of Controlled Release, vol. 82, no. 2-3, pp. 417-427, 2002.

[10] A. I. Khan, A. Ragavan, B. Fong et al., "Recent developments in the use of layered double hydroxides as host materials for the storage and triggered release of functional anions," Industrial and Engineering Chemistry Research, vol. 48, no. 23, pp. 1019610205, 2009.

[11] M. Silion, D. Hritcu, I. M. Jaba et al., "In vitro and in vivo behavior of ketoprofen intercalated into layered double hydroxides," Journal of Materials Science, vol. 21, no. 11, pp. 3009-3018, 2010.

[12] J.-H. Yang, Y.-S. Han, M. Park, T. Park, S.-J. Hwang, and J.-H. Choy, "New inorganic-based drug delivery system of indole-3-acetic acid-layered metal hydroxide nanohybrids with controlled release rate," Chemistry of Materials, vol. 19, no. 10, pp. 2679-2685, 2007.

[13] L. Lei, R. P. Vijayan, and D. O'Hare, "Preferential anion exchange intercalation of pyridinecarboxylate and toluate isomers in the layered double hydroxide $\left[\mathrm{LiAl}_{2}(\mathrm{OH})_{6}\right] \mathrm{Cl} \cdot \mathrm{H}_{2} \mathrm{O}$," Journal of Materials Chemistry, vol. 11, no. 12, pp. 3276-3280, 2001.

[14] B. Lotsch, F. Millange, R. I. Walton, and D. O'Hare, "Separation of nucleoside monophosphates using preferential anion exchange intercalation in layered double hydroxides," Solid State Sciences, vol. 3, no. 8, pp. 883-886, 2001.

[15] H. Tagaya, N. Sasaki, H. Morioka, and J. Kadokawa, "Preparation of new inorganic-organic layered compounds, hydroxy double salts, and preferential intercalation of organic carboxylic acids into them," Molecular Crystals and Liquid Crystals Science and Technology A, vol. 341, pp. 413-418, 2000.

[16] P. P. Kumar, A. G. Kalinichev, and R. J. Kirkpatrick, "Hydration, swelling, interlayer structure, and hydrogen bonding in organolayered double hydroxides: insights from molecular dynamics simulation of citrate-intercalated hydrotalcite," Journal of Physical Chemistry B, vol. 110, no. 9, pp. 3841-3844, 2006.

[17] S. V. Prasanna and P. V. Kamath, "Anion-exchange reactions of layered double hydroxides: interplay between coulombic and h-bonding interactions," Industrial and Engineering Chemistry Research, vol. 48, no. 13, pp. 6315-6320, 2009.

[18] Z. Gu, A. C. Thomas, Z. P. Xu, J. H. Campbell, and G. Q. Lu, "In vitro sustained release of $\mathrm{LMWH}$ from $\mathrm{MgAl}$-layered double hydroxide nanohybrids," Chemistry of Materials, vol. 20, no. 11, pp. 3715-3722, 2008.

[19] J. T. Rajamathi, S. Britto, and M. Rajamathi, "Synthesis and anion exchange reactions of a layered Copper-Zinc," Journal of Chemical Sciences, vol. 117, no. 6, pp. 629-633, 2005.

[20] M. Frisch, G. Trucks, H. Schlegel et al., "Gaussian 98, Revision A.11.4," 2002.

[21] S. Majoni and J. M. Hossenlopp, "Anion exchange kinetics of nanodimensional layered metal hydroxides: use of isoconversional analysis," Journal of Physical Chemistry A, vol. 114, no. 49, pp. 12858-12869, 2010.

[22] C. Chouillet, J.-M. Krafft, C. Louis, and H. Lauron-Pernot, "Characterization of zinc hydroxynitrates by diffuse reflectance infrared spectroscopy-structural modifications during thermal treatment," Spectrochimica Acta A, vol. 60, no. 3, pp. 505511, 2004.

[23] W. Fujita and K. Awaga, "Magnetic properties of $\mathrm{Cu}_{2}(\mathrm{OH})_{3}(\mathrm{al}-$ kanecarboxylate) compounds: drastic mod-ification with extension of the Alkyl chain," Inorganic Chemistry, vol. 35, no. 7, pp. 1915-1917, 1996.

[24] R. Świsłocka, M. Kowczyk-Sadowy, M. Kalinowska, and W. Lewandowski, "Spectroscopic (FT-IR, FT-Raman, ${ }^{1} \mathrm{H}$ and ${ }^{13} \mathrm{C}$ NMR) and theoretical studies of p-coumaric acid and alkali metal p-coumarates," Spectroscopy, vol. 27, no. 1, pp. 35-48, 2012. 
[25] T. Biswick, W. Jones, A. Pacuła, E. Serwicka, and J. Podobinski, "The role of anhydrous zinc nitrate in the thermal decomposition of the zinc hydroxy nitrates $\mathrm{Zn}_{5}(\mathrm{OH})_{8}\left(\mathrm{NO}_{3}\right)_{2} \cdot 2 \mathrm{H}_{2} \mathrm{O}$ and $\mathrm{ZnOHNO}_{3} \cdot \mathrm{H}_{2} \mathrm{O}$," Journal of Solid State Chemistry, vol. 180, no. 4, pp. 1171-1179, 2007.

[26] S.-H. Park and E. L. Cheol, "Synthesis, characterization and magnetic properties of a novel disulfonate-pillared copper hydroxide $\mathrm{Cu}_{2}(\mathrm{OH})_{3}(\mathrm{DS} 4)_{1 / 2}$, DS4 = 1,4-butanedisulfonate," Bulletin of the Korean Chemical Society, vol. 27, no. 10, pp. 15871592, 2006.

[27] P. Rabu, M. Drillon, and C. Hornick, "Structural and spectroscopic study of organic-inorganic transition metal based layered magnets," Analusis, vol. 28, no. 2, pp. 103-108, 2000.

[28] L. Lei, A. Khan, and D. O'Hare, "Selective anion-exchange intercalation of isomeric benzoate anions into the layered double hydroxide $\left[\mathrm{LiAl}_{2}(\mathrm{OH})_{6}\right] \mathrm{Cl} \cdot \mathrm{H}_{2} \mathrm{O}$," Journal of Solid State Chemistry, vol. 178, no. 12, pp. 3648-3654, 2005.

[29] W. Krause, H.-J. Bernhardt, R. S. W. Braithwaite, U. Kolitsch, and R. Pritchard, "Kapellasite, $\mathrm{Cu}_{3} \mathrm{Zn}(\mathrm{OH})_{6} \mathrm{Cl}_{2}$, a new mineral from Lavrion, Greece, and its crystal structure," Mineralogical Magazine, vol. 70, no. 3, pp. 329-340, 2006.

[30] L. C. Andrews, L. R. Bernstein, C. M. Foris et al., Powder Diffraction File, Inorganic, International Centre for Diffraction Data, Newtown Square, Pennsylvania, 2009.

[31] A. Ragavan, A. I. Khan, and D. O'Hare, "Isomer selective ion-exchange intercalation of nitrophenolates into the layered double hydroxide $\left[\mathrm{LiAl}_{2}(\mathrm{OH})_{6}\right] \mathrm{Cl} \cdot \mathrm{xH}_{2} \mathrm{O}$," Journal of Materials Chemistry, vol. 16, no. 6, pp. 602-608, 2006.

[32] A. Ragavan, A. Khan, and D. O'Hare, “Selective intercalation of chlorophenoxyacetates into the layered double hydroxide $\left[\mathrm{LiAl}_{2}(\mathrm{OH})_{6}\right] \mathrm{Cl} \cdot \mathrm{xH}_{2} \mathrm{O}$," Journal of Materials Chemistry, vol. 16, no. 42, pp. 4155-4159, 2006.

[33] S. Vyazovkin and C. A. Wight, "Model-free and model-fitting approaches to kinetic analysis of isothermal and nonisothermal data," Thermochimica Acta, vol. 340-341, pp. 53-68, 1999.

[34] R. E. Johnsen, F. Krumeich, and P. Norby, "Structural and microstructural changes during anion exchange of CoAl layered double hydroxides: an in situ X-ray powder diffraction study," Journal of Applied Crystallography, vol. 43, no. 3, pp. 434-447, 2010.

[35] G. R. Williams, T. G. Dunbar, A. J. Beer, A. M. Fogg, and D. O'Hare, "Intercalation chemistry of the novel layered double hydroxides $\left[\mathrm{MAl}_{4}(\mathrm{OH})_{12}\right]\left(\mathrm{NO}_{3}\right)_{2} \cdot \mathrm{yH}_{2} \mathrm{O}(\mathrm{M}=\mathrm{Zn}, \mathrm{Cu}, \mathrm{Ni}$ and Co). 1: new organic intercalates and reaction mechanisms," Journal of Materials Chemistry, vol. 16, no. 13, pp. 1222-1230, 2006.

[36] T. E. M. Ten Hulscher and G. Cornelissen, "Effect of temperature on sorption equilibrium and sorption kinetics of organic micropollutants-a review," Chemosphere, vol. 32, no. 4, pp. 609-626, 1996.

[37] M. Avrami, "Kinetics of phase change. I: general theory," The Journal of Chemical Physics, vol. 7, no. 12, pp. 1103-1112, 1939.

[38] M. Avrami, "Kinetics of phase change. II Transformation-time relations for random distribution of nuclei," The Journal of Chemical Physics, vol. 8, no. 2, pp. 212-224, 1940.

[39] R. J. Francis, S. O’Brien, A. M. Fogg et al., “Time-resolved insitu energy and angular dispersive X-ray diffraction studies of the formation of the microporous gallophosphate ULM-5 under hydrothermal conditions," Journal of the American Chemical Society, vol. 121, no. 5, pp. 1002-1015, 1999.

[40] Z. Miladinović, J. Zakrzewska, B. Kovačević, and G. Bačić, "Monitoring of crystallization processes during synthesis of zeolite A by in situ 27Al NMR spectroscopy," Materials Chemistry and Physics, vol. 104, no. 2-3, pp. 384-389, 2007.

[41] R. Serna-Guerrero and A. Sayari, "Modeling adsorption of $\mathrm{CO}_{2}$ on amine-functionalized mesoporous silica. 2: kinetics and breakthrough curves," Chemical Engineering Journal, vol. 161, no. 1-2, pp. 182-190, 2010.

[42] J. D. Hancock and J. H. Sharp, "Method of comparing solidstate kinetic data and its application to the decomposition of kaolinite, brucite, and $\mathrm{BaCO}_{3}$," Journal of the American Ceramic Society, vol. 55, no. 2, pp. 74-77, 1972.

[43] F. Auriemma, C. De Rosa, and R. Triolo, "Slow crystallization kinetics of poly(vinyl alcohol) in confined environment during cryotropic gelation of aqueous solutions," Macromolecules, vol. 39, no. 26, pp. 9429-9434, 2006.

[44] R. V. Ramanujan and Y. R. Zhang, "Quantitative transmission electron microscopy analysis of the nanocrystallization kinetics of soft magnetic alloys," Physical Review B, vol. 74, no. 22, Article ID 224408, 2006.

[45] A. G. Kalinichev, P. Padma Kumar, and R. James Kirkpatrick, "Molecular dynamics computer simulations of the effects of hydrogen bonding on the properties of layered double hydroxides intercalated with organic acids," Philosophical Magazine, vol. 90, no. 17-18, pp. 2475-2488, 2010. 

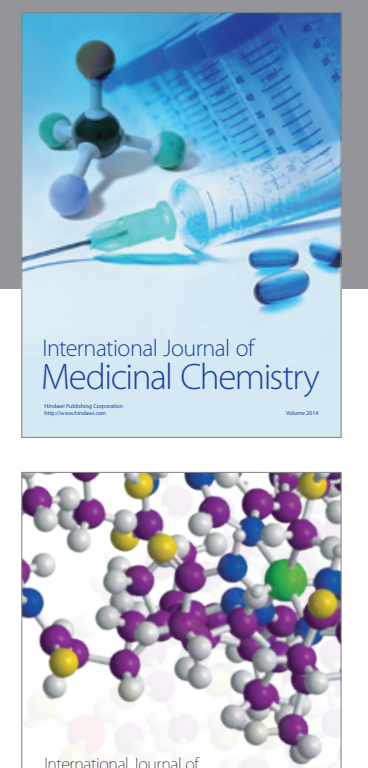

\section{Carbohydrate} Chemistry

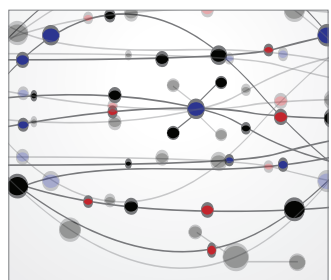

The Scientific World Journal
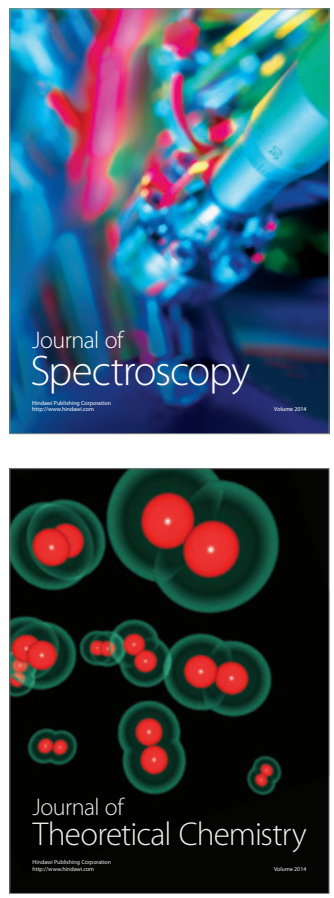
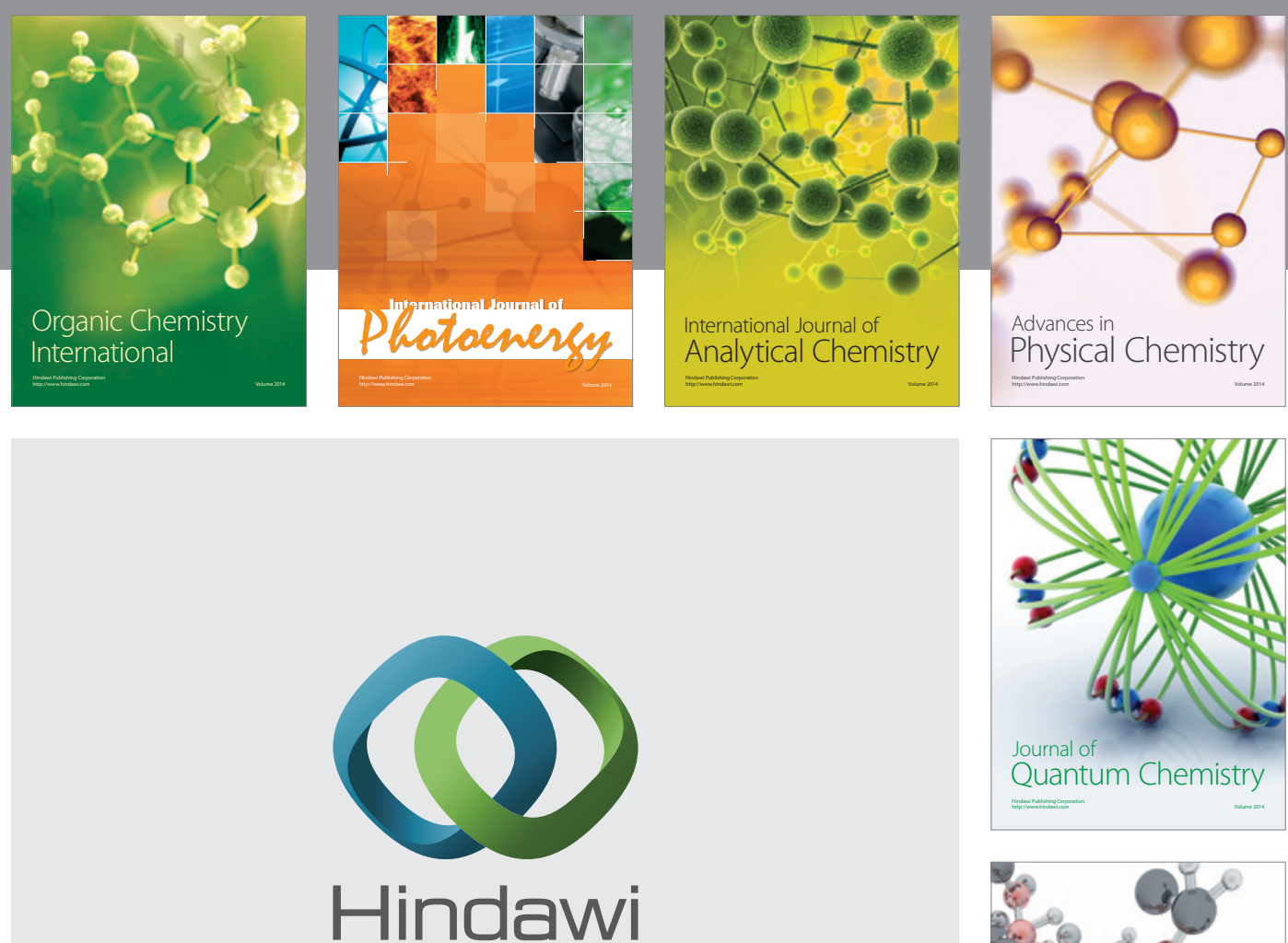

Submit your manuscripts at

http://www.hindawi.com

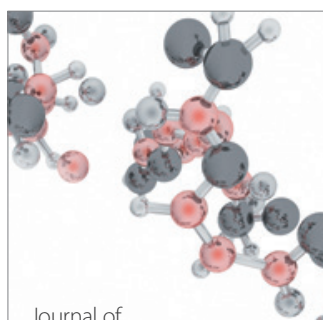

Analytical Methods

in Chemistry

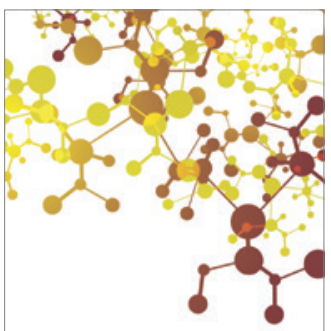

Journal of

Applied Chemistry

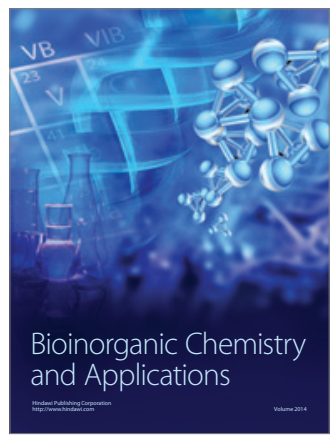

Inorganic Chemistry
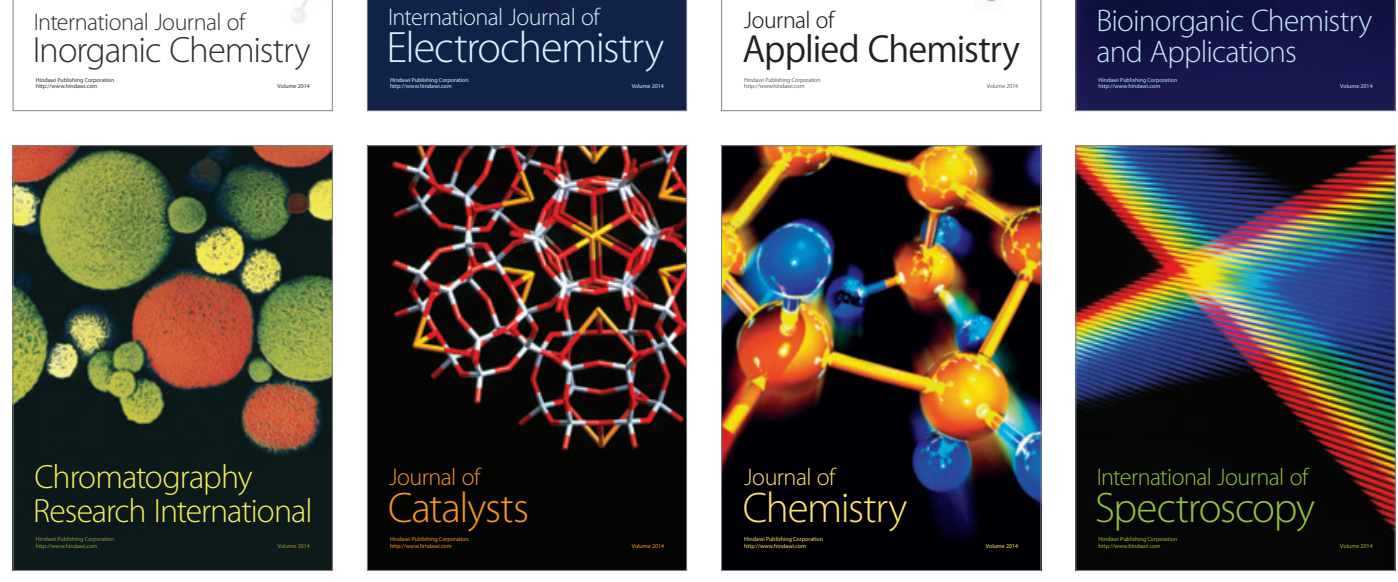